\title{
ОТ ВЗГЛЯДОВ Л.С. ВЫГОТСКОГО К СОВРЕМЕННОЙ КОНЦЕПЦИИ РАЗВИТИЯ
}

\author{
B.М. РОЗИН
}

${ }^{a}$ Институт философии РАН, 119019, Россия, Москва, ул. Гончарная, д. 12, стр. 1

\begin{abstract}
Резюме
В статье рассматривается концепция развития Л.С. Выготского. Обсуждаются ее недостатки с точки зрения современных научных представлений. Предлагается новая концепция развития, основанная на идеях шага развития, культурно-исторической и семиотической природы способностей и культуры жизни человека. Первая идея связана с различением экзистенциальных ситуаций, проблем, схем как средств разрешения этих проблем, новой реальности, ви́дения и действий. Вторая - с культурно-исторической и семиотической трактовкой способностей человека. Третья - с культурологической характеристикой этапов развития человека. Общие положения иллюстрируются на примере анализа нескольких кейсов. Среди общих положений ряд новых для психологии гипотез. Например, автор разбирает следующий важный для психологии момент. Аристотель в работе «О душе» создает антропологические схемы, задающие новую, мы бы сегодня сказали, психологическую реальность, которая заставляет греков использовать созданные им правила, категории и образцы мысли. Когда греки привыкли к новой деятельности и реальности (на это, кстати, ушло почти два века), им стало казаться, что мышление и есть именно такой феномен, о котором писал Аристотель, и оно всегда было у человека. Эту иллюзию ученые разделяют до сих пор. Автор утверждает, что и другие способности человека, например память, воображение, эмоции, тоже представляют собой не натуральные, исходно присущие человеку феномены, а культурно-исторические и семиотические образования. Другая гипотеза касается периодизации психического развития. Автор считает, что периодизация развития человека должна основываться не на концепции возраста, а на другой - «культуры жизни человека». Ссылаясь на свои работы, он утверждает, что единым человек является только в биологическом плане, как культурное и духовное существо человек - не един. Существуют несколько «культур жизни человека»: «культура детства», «культура отрочества и юности», несколько «культур взрослого человека». Каждая культура жизни человека характеризуется особенностями жизнедеятельности и ви́дения (сознания), а также характером социализации.
\end{abstract}

Ключевые слова: развитие, ситуация, проблемы, реальность, действия, понимание, ви́дение, культуры жизни, знаки, схемы.

Не будет преувеличением утверждать, что в настоящее время понимание развития человека и психики, которым мы пользовались в прошлом столетии, неудовлетворитель- но, вероятно, оно исчерпало себя. Приходится заново обсуждать, что собой представляет развитие, как его можно помыслить. Заново не означает - отбрасывая прежние взгляды, 
а переосмысляя их. В этом отношении большой интерес представляет концепция Л.С. Выготского.

В методологическом плане последняя самая большая работа Выготского «Мышление и речь» основывается как раз на его концепции развития. Поясняя в начале книги общую программу исследований, он пишет: «Объединяющим моментом всех этих исследований является идея развития...» (Выготский, 1982, c. 23). У Л.С. Выготского можно выделить два разных, по сути, не связанных между собой понимания развития. С одной стороны, развитие Л.С. Выготский трактует биологически, в этом случае он употребляет такие выражения, как «рост» (мышления, значений, понятий), «проращивание», «почка», «самодвижение», «отбор». В этой модели отсчет развития мышления начинается чуть ли не с животного мира или с самого раннего детства.

«Не является для марксизма, пишет Л.С. Выготский, - сколько-нибудь новым то положение, что в животном мире заложены корни человеческого интеллекта... во всяком случае, нет основания отрицать наличие генетических корней мышления и речи в животном царстве, и эти корни, как показывают все данные, различны для мышления и речи» (Там же, с. 112, 113).

В так понимаемом развитии мышления Л.С. Выготский различает отдельные этапы, промежуточные формы (ср. поиск промежуточных звеньев между человеком и обезьяной), незрелые, неустойчивые формы, которые постепенно созревают, усложняются, адаптируются к среде. $\mathrm{C}$ точки зрения подобной биологиче- ской концепции мышление в самой простой зачаточной форме (как почка, семя) присутствует уже у совсем маленького ребенка, когда он осваивает первые значения слов, и в сложной развитой (понятийной) форме - у подростка и взрослого. По мнению Л.С. Выготского, развивается мышление под влиянием причин и факторов, трактуемых сугубо в естественно-научном ключе. Впрочем, в данном вопросе Л.С. Выготский действует вполне последовательно, реализуя свою установку на построение психологии как точной естественной науки, которую он четко сформулировал в 1927 г. в работе «Исторический смысл психологического кризиса (методологическое исследование)».

Однако наряду с биологическим представлением о развитии в «Мышлении и речи» мы находим совершенно другое понимание развития, вероятно, сложившееся под влиянием философских идей: развитие как механизм осознания, как способ овладения с помощью знаков собственными психическими процессами.

«Проблема, - пишет Л.С. Выготский, - заключается именно в этом, ибо развитие состоит в прогрессирующем осознании понятий и операций собственной мысли» (Там же, с. 212). «Центральным для этого процесса, как показывают исследования, является функциональное употребление знака или слова в качестве средства, с помощью которого подросток подчиняет своей власти собственные психические операции, с помощью которого он овладевает течением собственных психических процессов и направляет их деятельность на разрешение стоящей перед ним задачи» (Там же, с. 132). 
Естественно ожидать, что Л.С. Выготский покажет, как связано первое квазибиологическое понятие, на основе которого он устанавливает основные закономерности развития детского мышления, со вторым понятием развития, а также каким образом оба эти понятия связаны с идеей использования слова-знака, понятия-знака. Однако в «Мышлении и речи» мы этого не находим.

Тем не менее отчасти все же можно понять, как Л.С. Выготский пытался связать введенные им два разных понятия развития: он предлагает различать развитие «эволюционного» и «революционного» типа. «Первый признак заключается в том, что при всяком изменении субстрат, лежащий в основе развивающегося явления, остается тем же самым... Единство как постоянство всего процесса развития, внутренняя связь между прошедшей стадией развития и наступившим изменением вот второй основной признак, который входит в понятие развития» (Выготский, 1983, с. 149). Дальше Л.С. Выготский замечает, что с точки зрения такого понимания второе понимание многие психологи не считают развитием, отказываются «рассматривать культурный опыт ребенка», «приучение», «усвоение» и «воспитание» как акты развития (Там же, c. 149). Но, говорит Л.С. Выготский, это тоже развитие, однако «революционного типа, иначе говоря, резкие и принципиальные изменения самого типа развития, самих движущих сил прогресса, а хорошо известно, что наличие революционных изменений наряду с эволюционными не является таким признаком, который исключал бы возможность прило- жить понятие развития к этому процессу» (Там же, с. 151).

Анализируя второе понимание развития у Л.С. Выготского, А.А. Пузырей «додумывает Выготского до конца». «Развитие тут, - пишет А.А. Пузырей, - стало быть, происходит только в той мере, в которой совершается некоторое действие, направленное на развитие, то есть здесь “нечто" развивается в силу того, что его “развивают”... Это “процесс”, имеющий непременную "искусственную” компоненту - компоненту специального нашего действия. Мы должны были бы говорить здесь об особого рода действиях по перестройке или реорганизации психологического аппарата или режимов его работы. Еще раз: подобного рода действия можно назвать "психотехническими” действиями. Психика человека сама по себе, по мысли Л.С. Выготского, не имеет своих собственных законов развития и больше того - вообще не обладает развитием. Психическое и духовное развитие человека происходит всегда за счет особых, специально организуемых (вырабатываемых в истории и закрепляемых в культуре в самых различных подчас весьма неожиданных и экзотических формах) искусственных систем психотехнического действия, т.е. действия над психикой, т.е. действия по овладению и изменению психики с помощью применения специальных искусственных знаковых средств» (Пузырей, 1968, c. 85-86).

А.А. Пузырей, конечно, прав, утверждая, что исследование может быть разным, в частности, ориентированным на психотехническое развитие нового человека. Л.С. Выготский 
периодически формулировал установку на подобное развитие, тем не менее его исследование этой установке не отвечало. Зато он последовательно реализовал естественнонаучный подход. Впрочем, я не совсем точен. В «Истории развития высших психических функций» Л.С. Выготский действительно выстраивает такую онтологию, которая отвечает психотехнической установке. Но установке, не противоречащей естественно-научному подходу, как это утверждает А.А. Пузырей, а, напротив, реализующей именно ее, причем строго и дважды.

Так, Л.С. Выготский, с одной стороны, проводит аналогию между отношением человека-инженера к природе (такой человек овладевает природными процессами с помощью орудий и машин) и отношением развивающегося ребенка к своей собственной психике и поведению (которыми ребенок овладевает, научается управлять с помощью орудий-знаков). «Каждой определенной ступени в овладении силами природы необходимо соответствует определенная ступень в овладении поведением, в подчинении психических процессов власти человека... Человек вводит искусственные стимулы, сигнифицирует поведение и при помощи знаков создает, воздействуя извне, новые связи в мозгу» (Выготский, 1983, с. 80).

С другой стороны, Л.С. Выготский ту же самую аналогию, правда, расширяя ее, распространяет и на отношения «внешнее - внутреннее», «социальное - психическое», доказывая, что интериоризация социального опыта и отношений по сути есть механизм воздействия активной социальной среды («социального инженера» - родителя, педагога, друзей и т.д.) на психику ребенка, который в результате этого развивается. По мнению Л.С. Выготского, всякая функция человеческой психики первоначально складывается как внешняя, социальная форма общения между людьми, как трудовая или иная деятельность, и лишь затем, в результате интериоризации, становится компонентом психики человека. Не случайно, что в работе «Мышление и речь» Л.С. Выготский цитирует Жане, утверждающего, по мнению Л.С. Выготского, что «за властью слова над психическими функциями стоит реальная власть начальника и подчиненного, отношение психических функций генетически должно быть отнесено к реальным отношениям между людьми. Регулирование посредством слова чужого поведения постепенно приводит к выработке вербализированного поведения самой личности» (Выготский, 1982, с. 142).

Проводя глубокую аналогию внутреннего и психического с природными процессами, на которые воздействует инженер (один раз в форме социального опыта, а другой - активности самого ребенка), Л.С. Выготский, с одной стороны, может приписывать психике законы и имманентные изменения, т.е. развитие, напоминающее биологическое, с другой - утверждать, что использование знаков и интериоризация социального опыта как раз и запускают эти законы и изменения. Подобная психотехническая установка и онтология, безусловно, способствуют формированию нового («возможного») человека, но совсем не такого, 
которого подразумевает А.А. Пузырей. Новый человек, по Л.С. Выготскому, вполне вписывается в вариант идеологического техницизма и марксизма, это инженер чужих и своей душ, вполне чуждый духовности и гуманитарной культуры. Мне такой подход чужд, хотя ряд идей Л.С. Выготского о роли знаков, перестройке психики, интериоризации социального опыта, развитии высших психических функций представляются интересными. Попробую теперь ввести основные положения о развитии, опирающиеся на мои методологические, культурологические, семиотические и антропологические исследования.

Первое, что стоит пересмотреть, понимание факторов, обусловливающих развитие человека в культуре. Не только обучение, но и СМИ, и семья, и Әрузья, и во многих случаях самостоятельные поиски, чтение, размышления о своей жизни (другими словами, нужно учитывать еще один важный фактор - личность индивида). Да и обучение не равно само себе: одно дело дошкольное и начальное обучение, другое - среднее, третье - высшее, четвертое гуманитарное, пятое - техническое, шестое - экономическое, седьмое в идеологии тьюторства и т.д.

Вторая линия переосмысления, пожалуй, даже более существенная. Теоретические представления о развитии Л.С. Выготского и современных исследователей (философов, психологов, педагогов), к сожалению, не выглядят убедительными, не вообще, а с точки зрения вызовов времени и методологии, а также результатов многочисленных исследований в разных научных дисцип- линах. Например, что значит овладение собственным поведением? Оно уже сложилось и его надо только описать, тогда причем здесь знаки как орудия преобразования психики? Или именно демонстрация внешних социальных отношений и действий, подкрепленных использованием знаков, формирует (конституирует) внутренний план психики? Но в этом случае что значит овладение? А как Л.С. Выготский понимает, что такое знак? Орудийное понимание знака трудно соотнести с представлениями современной семиотики.

Легко критиковать других, а вот что скажет сам автор? Начну я с такого положения. В развитии происходит не овладение собственным поведением, а его конституирование, не знаки здесь главное, а схемь. Схемы (чаще нарративные, чем графические) позволяют разрешить проблемы, вставшие перед человеком; в свою очередь проблемы кристаллизуются в экзистенциальных ситуациях, которые проживает человек. Изобретение новых или заимствование из культуры существующих схем позволяет переорганизовать внутренний опыт человека, в результате чего меняется его ви́дение реальности и понимание. Психологически это воспринимается как открытие новых реалий (объектов, предметов, событий), а иногда - попадания в новый мир. Новое ви́дение и понимание - условие и новых действий (поступков).

На рисунке 1 приведен один из «тактов развития». Понимаю, все это достаточно абстрактно, поэтому для облегчения понимания приведу один кейс. 
Такт развития

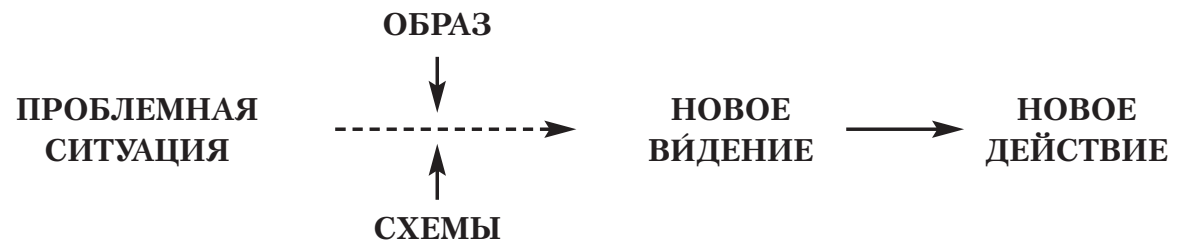

Главный герой романа «Воскресение», князь Дмитрий Иванович Нехлюдов, еще будучи студентом, гостит у своих теток и соблазняет их 16-летнюю полугорничную, полувоспитанницу Катюшу Маслову. Сунув ей в последний день сторублевую бумажку, он уезжает. Катюша узнает, что она беременна, уходит от своих барышень-хозяев, а дальше ее судьба складывается очень печально. Ребенок умирает, и после ряда жизненный перипетий Маслова оказывается в доме терпимости. Семь лет спустя ее судят по подозрению в отравлении купца Смелькова, который весь день накануне и последнюю ночь перед смертью провел с Масловой в доме терпимости. Нехлюдов с ужасом узнает в подозреваемой соблазненную им девушку. Хотя Маслова была невиновна, но судебная ошибка приводит к тому, что ее осуждают на каторгу. Во время суда и после него в душе Нехлюдова идет борьба, которая заканчивается решением князя изменить свою жизнь и искупить вину перед Катюшей, что Нехлюдов и делает.

«Как загладить свой грех перед Катюшей? Нельзя же это оставить так. "Нельзя бросить женщину, которую я любил, и удовлетвориться тем, что заплачу деньги адвокату и избав- лю ее от каторги, которой она и не заслуживает, загладить вину деньгами, как я тогда думал, что сделал, что должно, дав ей деньги”.

И он живо вспомнил минуту, когда он в коридоре, догнав ее, сунул ей деньги и убежал от нее. “< ...>- Только мерзавец, негодяй мог это сделать! И я, я тот негодяй и тот мерзавец! вслух заговорил он. - Да неужели в самом деле, - он остановился на ходу, - неужели я в самом деле, неужели я точно негодяй? А то кто же? - ответил он себе. <...

"Разорву эту ложь, связывающую меня, чего бы это мне ни стоило, и признаю все и всем скажу правду и сделаю правду, - решительно вслух сказал он себе. <...>

Он молился, просил Бога помочь ему, вселиться в него и очистить его, а между тем то, о чем он просил, уже совершилось. Бог, живший в нем, проснулся в его сознании. Он почувствовал себя им и потому почувствовал не только свободу, бодрость и радость жизни, но почувствовал все могущество добра. Все, все самое лучшее, что только мог сделать человек, он чувствовал себя теперь способным сделать» (Толстой, 1948).

Так все это выглядит для развивающегося человека. Перед нами настоящий такт развития. Что его 
инициировало, запустило? Экзистенциальная ситуация, в которой оказался Нехлюдов; проблемы, возникшие при этом (как совместить любимый образ себя со своим же реальным поступком и его страшными последствиями, каким образом все исправить, можно ли это сделать, можно ли отказаться от своей привычной комфортной жизни и др.). Разрешает эти проблемы (пока в плане сознания) Нехлюдов с помощью разворачиваемых им нарративных схем: «только мерзавец, негодяй мог это сделать! И я, я тот негодяй и тот мерзавец!; да неужели в самом деле, неужели я в самом деле, неужели я точно негодяй?; а то кто же?; разорву эту ложь, связывающую меня, чего бы это мне ни стоило, и признаю все и всем скажу правду и сделаю правду». Выстроенные схемы кардинально переорганизуют внутренний мир (опыт) нашего героя, они вводят его в новую реальность, где есть Бог, совесть, желание искупить свою вину. Из романа мы знаем, что Нехлюдов нашел в себе силы именно так и поступить.

Кто-то может возразить, сказав, что нельзя сравнивать действия и поступок Нехлюдова, например, со школьными ситуациями. Я бы не согласился. Подлинное образование (и обучение), как правило, вовлекает учащихся в экзистенциальные ситуации, заставляет их изобретать схемы, приобщает к новым событиям, иногда вводит в новый мир. Более того, как я показываю в статье о детстве, построение схем доступно и детям, которые ими как бы мыслят (Розин, 2015б).

Если читатель принял эту гипотезу, то он, естественно, может спро- сить: каким это образом схемы переорганизуют психику человека, что при этом происходит в плане развития индивида? Фактически на этот вопрос я отвечал в одной из своих первых книг «Визуальная культура и восприятие. Как человек понимает и видит мир». Там я разбирал феномен открытия маленьким ребенком изображения: сначала он не видит, что изображено, а просто линии и краски на бумаге, но вскоре открывает в них изображаемое (солнышко, траву, людей и пр.). Я показывал, что проблема, с которой ребенок столкнулся, а именно он не видит в рисунке то, о чем ему говорит взрослый (ни солнышко, ни зеленую траву, ни людей), заставляет его, во-первых, искать эти предметы, во-вторых, рано или поздно актуализировать свой опыт восприятия соответствующих предметов на определенных формах (линиях, красках). Тогда он прозревает, начинает видеть в этих формах солнышко, траву, людей. Обратим внимание, ведь изображаемые предметы (реальное солнце, трава, люди) ничего общего не имеют с графическими и колористическими формами, тем не менее ребенок почему-то увидел в них предметы, названные взрослым (Розин, 2015а). Спрашивается, почему, как это ему удалось?

Не потому ли, что, зацепившись за небольшое сходство форму, которая, кстати, стала видна лишь после того, как ребенок в поисках указанных предметов соединил их в своем воображении с линиями и красками на бумаге, наш герой смело приписал этим линиям и краскам сами предметы? Приписал, в смысле актуализовал (реализовал, воплотил) их в новой для них графической и колористической 
форме. Уже Гельмгольц установил, что наше ви́дение состоит из двух компонент - сложившегося опыта восприятия предмета и получения о нем визуальной информации. Я же в работах, посвященных объяснению природы сновидений и искусства, утверждаю, что в ряде случаев опыт восприятия предмета может актуализоваться без опоры на визуальную информацию. Может он реализоваться и не на своем «родном материале», а, скажем, «семиотическом», например графическом. Психологически же человек осозна́ет этот процесс как появление нового предмета (Розин, 2015а; см. также: Розин, 2011, с. 256-384).

Другими словами, разрешая свою проблему, ребенок творит новые предметы - рисуночные солнышко, траву, людей. Получается, что переорганизация психики происходит в результате решения проблем, изобретения схем (в данном примере это нарисованное солнце, трава, люди), актуализации имеющегося у индивида психического опыта (ви́дения, слышания, ощущения) в материале знаков и схем, причем переорганизация никогда бы не произошла без помощи взрослых и желания ребенка не выпасть из коммуникации (уж если мама или папа говорят, что на бумаге есть солнышко, то, значит, его надо найти). В этом смысле переорганизация - процесс как субъективный, творческий, так и интерсубъективный, поставляющий сложившиеся знаки и схемы, заставляющий искать решение проблемы. Часто, как я показываю в статье «Детство как культурный и психологический феномен» (Розин, 2015б), дети, решая свои проблемы, сами изобретают схемы, причем очень оригинальные. Само собой, что изобретением новых схем заняты ученые и художники, да и представители других профессий и практик.

Вторая наша идея состоит в том, что концепция интериоризации (усвоения) себя исчерпала и даже является тормозом. Она пришлась ко двору в социалистическом государстве с его идеями формирования нового социалистического человека (и Л.С. Выготский писал, что психология будет первой наукой, которая позволит создать нового человека и тем самым решить задачу, поставленную марксизмом). Социализация человека происходит не путем интериоризации внешних содержаний и деятельности, а построения учащимися собственных реальностей и действий, разворачивающегося, в частности, под влиянием образования. Приведу один пример.

На третьем курсе пединститута я пошел преподавать физику в школу. Я и сам не любил решать физические задачи, и знал, что и у моих учеников это получается плохо. Кроме того, мне казался неправильным метод обучения, когда учитель показывает, как решаются задачи одного типа, а затем учащиеся решают по 20-30 однотипных задач, пока как-то не овладевают методом (некоторые так и не научаются решать). Следуя концепции Г.П. Щедровицкого, утверждавшего необходимость изучения мышления, я решил изменить способ обучения задачам. Сначала проанализировал и представил в схемах способы решения задач определенного типа. Затем на двух-трех примерах показал своим ученикам, каким образом решается задача определенного 
типа и как этот способ можно представить в схемах. Следующий шаг опять на двух-трех примерах мы разбирали способ применения схем для новых случаев (тот же тип задач, но с другими данными). Последний шаг учащиеся сами начинали решать задачи, используя схемы способа решения. Результат оказался прекрасным: я сократил вдвое время обучения задачам и почти все относительно легко научались их решать.

Можно ли этот процесс считать процессом интериоризации? Думаю, нет. Во-первых, различались способы решения (обычно задачи решаются без схем, а мои ученики стали решать задачи, освоив сначала на схемах способ решения). Во-вторых, они должны были сами научиться, т.е. открыть для себя новую реальность способа решения и его применения. Обычный способ решения однотипных задач меня не устраивал, но, конечно, новый способ решения я взял не с потолка, а получил на основе анализа и схематизации существующих решений однотипных задач. Чтобы ученики взяли этот новый способ, я погружал их в проблемную ситуацию (они не понимали, каким образом решать поставленные перед ними задачи) и затем помогал искать решение, предлагая соответствующие схемы способа решения. Мне могут возразить, сказав, что не надо было предлагать новый способ решения, лучше осваивать существующие. Однако, если этого не делать, педагог обрекает ученика искать непонятно что и непонятно где.

Стоит учесть и такое обстоятельство: наши способности сложились именно на основе схем и знаковых систем. Например, что такое мышление? Оно формируется в античной культуре как способ решения проблем и построения непротиворечивых знаний. Завершает эту работу Аристотель, создав правила рассуждения и познания, а также категории и продемонстрировав образцы нового подхода. При этом он столкнулся с такой проблемой. Греки не хотели рассуждать и получать знания, пользуясь аристотелевскими правилами, категориями и образцами. Тогда Аристотель пишет работу «О душе», утверждая, что у человека есть особая способность - мышление, причем оно устроено таким образом, что предполагает обязательное использование аристотелевских правил и категорий.

Аристотель хочет подключить человека к созданной им логике, оправдать новый взгляд на вещи и эмпирию, выраженные с помощью категорий и понятий, объяснить, как создаются знания, категории и понятия. Восприятие (ощущение), по Аристотелю, решает задачу связи вещей и эмпирии с категориями и понятиями, воображение позволяет понять, как на основе одних знаний и понятий получаются новые, а мышление трактуется именно как деятельность человека, пользующегося логикой, категориями и понятиями. Обсуждая, например, в «Аналитиках» способность к познанию начал, Аристотель указывает на индукцию, «ибо таким образом восприятие порождает общее» (Аристотель, 1952, с. 288). Но сходно Аристотель определяет в работе «О душе» ощущение как способность: «Ощущение есть то, что способно принимать формы чувственно воспринимаемых 
предметов без их материи, подобно тому, как воск принимает оттиск печати без железа и без золота» (Аристотель, 1936, с. 73). Ясно, что восприятию (ощущению) Аристотель приписывает здесь такие свойства, которые позволяют понять связь начал с вещами и работой чувств.

Тот же ход он реализует относительно мышления. «Мышление о неделимом, - по Аристотелю, относится к той области, где не может быть лжи. А то, где [встречаются] и ложь и истина, представляет собой соединение понятий... Впрочем, не всегда ум таков, но ум, предмет которого берется в самой его сути, [всегда усматривает] истинное, а не только устанавливает связь чегото с чем-то» (Там же, с. 97, 99).

Другими словами, мышление, по Аристотелю, - это и есть рассуждения по правилам с использованием категорий. Важно, что именно категории и понятия задавали в мышлении подлинную реальность, причем эта реальность оказывалась идеальной и конструктивной.

Можно отметить и такой интересный для психологии момент. Аристотель создает антропологические схемы, задающие новую, мы бы сегодня сказали, психологическую реальность, которая заставляет греков использовать созданные правила, категории и образцы мысли. Когда греки привыкли к новой деятельности и реальности (на это, кстати, ушло почти два века), им стало казаться, что мышление - именно такой феномен, о котором писал Аристотель, и оно всегда было у человека. Эту иллюзию даже ученые разделяют до сих пор. Как я показы- ваю, и другие способности человека, например память, воображение, эмоции, тоже представляют собой не натуральные, исходно присущие человеку феномены, а культурноисторические и семиотические образования (Розин, 2007, с. 269-341; 2015в).

И в случае обучения формированию способностей, например способности решать физические задачи, необходимо, с одной стороны, освоение определенных операций, схем и действий с ними, а с другой - обнаружение самой реальности решения задач и способов их решения.

Третья основная наша идея такова: периодизация развития человека должна основываться не на концепции возраста, а на другой - «культуры жизни человека». В статье о детстве я пишу, что единым человек является только в биологическом плане, как культурное и духовное существо человек не един. Существуют несколько «культур жизни человека»: «культура детства», «культура отрочества и юности», несколько «культур взрослого человека». Каждая культура жизни человека характеризуется особенностями жизнедеятельности и ви́дения (сознания), а также характером социализации; в первых двух культурах важное место отводится образованию.

Детство - это не только самостоятельная культура жизни, но и начало трудного перехода от одной жизни к другой (от «прамы» к личности). В детстве два основных способа освоения мира: игра и становление первых сочиально значимых практик (умения есть, пить, говорить, одеваться, общаться с взрослыми, помогать им и т.п.). В Я ребенка 
имплицитно входят и его родители, которые могут быть рассмотрены как его «социальное тело». Но сегодня чуть ли не главный воспитатель среда, гедонистически ориентированная культура. Мы, взрослые, сами не знаем, как жить. Отсюда детство - это «переход в переходы», в неопределенность. Как я уже отмечал, «мыслит» ребенок схемами.

Отрочество и юность - не менее самостоятельная культура жизни. Ее центральный процесс, во всяком случае в нашей новоевропейской культуре, - становление личности (не развитие личности, а только постепенное ее складывание через пробы и ошибки). Подростковая культура начинает формироваться, когда родители (общество) посылают ребенка в школу, где от него требуют действовать самостоятельно. В значительной степени и школа, и родители блокируют теперь для отрока возможность решать свои проблемы в сфере игры и фантазии (сказки). Напротив, объем обучения постоянно возрастает, а требование действовать рационально становится основным. Существенно изменяются и социальные отношения: вместо родительской опеки и поддержки складываются двусторонние властные (с педагогами и значимыми взрослыми) и равноправные (с друзьями) отношения.

Под давлением взрослых и школы распадается прамы, отрок начинает переходить к самостоятельному поведению, учится управлять сам собой (планирует свои занятия, позиционируется по отношению к другим, центрирует мир на своем Я, разделяет внутреннее и внешнее, происходят и прочие метаморфозы, достаточно хорошо описанные в художественной и психологической литературе). Отрочество неотделимо от школы и образования, в связи с чем на первый план выдвигается не игра, а рациональные типы поведения (учеба, рассуждения, первые анализы последствий своих поступков и пр.).

У подростка самостоятельное поведение, опирающееся на образ себя, часто входит в противоречие с его реальным поведением и отношениями, которые сформировались в этот период. Возникшие при этом проблемы вызывают как негативные переживания, так и особые формы поведения - упрямство, конфликты, отрицание взрослых, самоуничижение, стремление любой ценой доказать свою значимость и т.п. Но рано или поздно эти проблемы приводят к уточнению или смене образа себя, в результате чего начинается новый цикл развития подростка. Через такую неоднократную смену образа себя подросток нащупывает более реалистическую позицию в мире взрослых и осваивает более реалистические формы поведения (Розин, 2015б).

Взрослый человек - это сформированная личность, что не означает невозможности ее пересмотра (см. тот же пример с Нехлюдовым). Последний этап культуры взрослого человека - «культура старости». Как культура жизни старость складывается при условии, что общество признает своеобразие жизни пожильх людей и создает спещиальнье условия для такой жизни (пенсии, социальное и медицинское обслуживание, определенные законы, льготы, забота со стороны семьи и пр.). Другое 
условие - усилия и работа самих пожильх людей и стариков: выстраивание своего рода концепции старости и ее реализация. Третье - осмысление старости в культуре (литература, музыка, наука и пр.), создание, так сказать, «семиотики старости».

Так вот, если говорить о развитии, то оно по-разному протекает в разных культурах человека и резко меняется при переходе от одной культуры к другой. Различны в каждой культуре экзистенциальные ситуации и проблемы, с которыми человек сталкивается и которые разрешает. Различны способы их разрешения и схемы. Как следствие различны в каждой культуре жизни реальности и миры человеческого существования. По-разному развитие идет и в случае разных видов образования. Скажем, дошкольное и начальное школьное образование в основном представляет собой формирование, а высшее, а также с тьюторским сопровождением, наоборот, самообразование с участием и помощью педагога (Розин, 2014, с. 47-60).

Но что собой представляет само развитие, ведь не только такты изменений? Вероятно, это направленность шагов развития, так сказать, логика их трансформаций. От чего же они зависят? Ну, во-первых, как я утверждаю здесь, от особенностей культуры жизни. Во-вторых, от социального воздействия (образование, СМИ, семья, друзья), то, что обычно называют социализацией. В свою очередь, направленность образования определяется ее практиками и концепциями. В-третьих, развитие человека существенно зависит от его личности, поскольку она - источник самостоятельного поведения, лич- ность выстраивает свою жизнь и понятный личности мир.

Один из примеров - развитие Павла Флоренского. Судя по воспитанию и увлечениям, юный Павел должен был вырасти полным атеистом и ученым с физикалистской ориентацией. Отец, которого Павел очень любил, ориентировал сына на занятия естествознанием, тщательно избегал тем, касающихся веры в Бога, а сам Павел основное свое школьное время посвятил физике и другим естественным наукам, что и закономерно привело его на физико-математический факультет Московского университета (окончил в 1904 г.).

И вдруг, когда Павел оканчивал тифлисскую гимназию, на поверхность его сознания вышла, прорвалась религиозная реальность, а старый мир, построенный на догматах науки, рухнул. Сначала на фоне неясных переживаний и тоски Павлу во сне пришла весть («...тончайший луч, который был незримым светом, не то - неслышным звуком, принес имя - Бог» (Священник Павел Флоренский, 1992, с. 195), которую по пробуждению он осознал так. «Мне это было откровением, открытием, ударом. От внезапности этого удара я вдруг проснулся, как разбуженный внешней силой, и, сам не зная для чего, но подводя итог всему пережитому, выкрикнул на всю комнату: “Нет, нельзя жить без Бога" » (Там же, с. 212) (это восклицание не что иное, как схема, разрешившая центральную проблему Павла). В целом описанный переворот выглядит как неожиданный и ничем не обусловленный. Но посмотрим внимательнее. Была в образовании Павла одна особенность - необычное 
отношение к природе и ее освоение, природа понималась как живое существо и познавалась не отвлеченно, а проникновенно, пере-живательно, по-гётевски. Павел неоднократно подчеркивает, что любимым автором отца был Гёте, да и его тоже.

А вот в какую экзистенциальную ситуацию попал П. Флоренский. В те и последующие годы он все больше ощущал противоречие между естественно-научным мировоззрением $и$ своим реальным отношением к природе и жизни, между культивируемой отиом семейной замкнутостью и реальной жизнью вокруг. Живое, экстатическое отношение к природе и погружение в богатство истории и культуры человечества никак не укладывались в сознании Павла в естественно-научную картину мира с ее жесткими единообразными законами. Чувство любви и уважения к человеку, погружение в историю и культуру не соответствовали семейной изоляции от общества. Терпимость и плюрализм отцовского мировоззрения, и Павел это чувствовал, не отвечали общей тенденции того времени участвовать в социальных преобразованиях, тенденции, основанной на естественно-научном мировоззрении и связанных с ним идеях социальной инженерии.

И вот когда Павел стал подрастать и задумываться над смыслом своей жизни, он почувствовал, что уже не может совмещать эти два понимания жизни, что в нем как бы против его воли вырастает новая реальность. Почему она была осознана в религиозном ключе? Это понятно, ведь идея Бога для Павла не только была тайной, но и оказалась отвечающей многим его устремлениям.
Действительно, Бог не только создал природу, но и пребывает в ней как живое начало, Бог олицетворял любимую Павлом семью (Отец, Сын, Богоматерь), но не узко, а, напротив, вселенски; размыкая тесный мир Флоренских, Бог вносил единство и смысл в хаос жизни и много чего еще.

Однако и старая реальность никуда не ушла, и Павел оказался распятым на кресте своих противоречивых устремлений - и к Богу, и к науке. В середине 1920-х гг. Павел Флоренский пишет об этом так: «Это была характерная болезнь всей новой мысли, всего Возрождения; теперь, задним числом, я могу определить ее как разобщенность человечности и научности. Бесчеловечная научная мысль - с одной стороны, бессмысленная человечность с другой... Во мне эти две стихии столкнулись с особой силою, потому что возрожденческая научность была не внешним придатком и не оперением, а второю натурою, и ее истинный смысл я понимал не потому, что научился от кого-то, а знал непосредственно, как свои собственные желания. Но этому пониманию противостоял не менее сильный опыт, возрожденческие замыслы в корне их отрицающий” (курсив мой. - B.P.) (Там же, с. 217-218).

Однако новая реальность (опыт) еще была достаточно непонятной и противоречивой: что значит Бог в трех лицах, как он воплотился в человеке, что значит воскресение из мертвых, где теперь искать новую семью и прочие животрепещущие вопросы, на которые ответ могли дать только Священное Писание, святоотеческая литература, жизненный опыт и собственная мысль. 
Поступая в Московский университет, Павел уже знал истину (подлинную реальность), но он в ней пока не укрепился, не прожил ее мышлением, никак иначе он не мог принять ни христианство, ни веру. Требовалась большая творческая работа не только по мыслительному и душевному освоению реальности Бога, но и по разрешению всех противоречий, связанных с принятием христианской веры. Именно этим Флоренский и занимается в дальнейшем: создает христианское учение, в котором разрешаются все основные его противоречия.

Примерно такое же решение принял задолго до Флоренского Эмануэль Сведенборг, включивший естественно-научные представления в христианское учение. А вот св. Августин в раннем Средневековье решает эту проблемы совершенно иначе. Он полностью уходит от рационального античного мышления в христианство. Можно предположить, что решение кардинальных экзистенциальных проблем личности отчасти ее и формирует

Мы видим в истории с Павлом Флоренским действие всех трех факторов, определяющих развитие человека: культуру подростковой жизни, образование и личность самого Павла Флоренского.

Последний вопрос: почему так трудно говорить о развитии человека в настоящее время, особенно в нашей стране? Потому, что мы живем в эпоху перехода и социальных кризисов, когда однозначное направление социализации и образования задать практически невозможно. Потому, что претерпевает метаморфозы культура жизни человека. Наконец, и потому, что личность не знает, куда ей идти. В условиях неоднородной социальной и культурной среды, кризиса семьи и школы формирование нормальной личности, например, в России предельно затруднено. Многим подросткам недостает в семье любви и поддержки, а дальше с тем же отношением они часто сталкиваются и в школе. Родители, как правило, сами не могут разобраться в существующей социальной действительности, улица многолика, СМИ выбрасывают сценарии и образцы поведения, малопригодные для нормальной жизни. Общее снижение культуры, с одной стороны, и культивирование виртуальных форм жизни (игры, кинофильмы и пр.), с другой, способствуют формированию очень условных, странных, а нередко и девиантных структур сознания и форм поведения. В этой сложной ситуации каждый развивается, как может, а во многих случаях о развитии человека не приходится и говорить.

И все же определенный возможный тренд образования, а следовательно, и развития можно помыслить. Поскольку мы живем в условиях перехода, смены цивилизации, нетрудно предположить, что человек будет жить в другом мире - новом или обновляющемся. Какой этот мир будет конкретно - неизвестно, но он родится не без наших с вами усилий (лично каждого из нас и всех нас вместе). Кроме того, этот мир хотя и будет другим, предпосылками его выступит современность и наша история. Все это означает, что новыци человек (не какой-то там ницшеанский сверхчеловек, а каждый из нас, если захочет пойти по этому пути) должен быть человеком конструктивным и креативным, ведь ему придется 
конституировать новую реальность и жизнь. И одновременно он должен быть человеком культуры и истории, поскольку новая жизнь рождается не на пустом месте, в ней воспроизводится все то, что с исторической точки зрения оказалось инвариантным (разделение труда, познание и техника, личность и пр.), что будет работать в новых условиях, что можно переосмыслить и спасти для следующих поколений. Другими словами, все основные исторические и культурные реалии должны быть переосмыслены, во всех них новый человек должен установиться заново как личность.

Но человек не только личность, но и член социума, социальный индивид, и в этом качестве он нуждается в поддержке общества, в трансцендентальных смыслах и деиндивидуальных источниках энергии, которые новый человек, конечно, может найти готовыми, идентифицировав себя с какими-то социальными образованиями (это один из вариантов возможной новой жизни), но более правильный путь - конституирование собственной социальной среды, создание собственных жизненных ресурсов. Подобно современной корпорации, новый человек должен стать менеджером самого себя, создать собственный мир и траекторию жизни, способствовать становлению новых форм сообщительности, но и это принципиально - с опорой на общие условия, на других и общество. При этом, поскольку новый человек заинтересован в качестве и характере этих общих условий, он должен активно включаться в жизнь общества, в политическую жизнь, уметь влиять на других людей, достигать компромисса или консенcyca.

Можно указать и базовые способности нового человека. Способности воображения, без них трудно помыслить новые реальности и проживать их события. Способности рефлексии, позволяющие «останавливать» и артикулировать сложившиеся формы жизни, а также перестраивать их. Целый спектр способностей, дающих возможность, с одной стороны, учиться и переучиваться, с другой заниматься самообразованием. Креативные способности (познавательные, проектные, организационные и др.), необходимые для практического воплощения новых идей и представлений. Спектр коммуникационных способностей - понимание, общение, разрешение конфликтов, достижение компромиссов, осуществление совместной деятельности, размежевание и др. Наконец, способности к личностной навигации, включая самоопределение, осознание своей обусловленности и ценностей, преодоление себя, идентификацию и разотождествление с определенными субъектами, выстраивание собственного скрипта, сопровождение его, разрешение экзистенциальных проблем и др.

Можно указать также некоторые черты желаемого образования. Оно должно воспроизводить центральные особенности современности (многообразие форм жизни, возможность выстраивать индивидуальную личную траекторию, корпоративность, сетевая сообщительность, культура современного мышления и пр.). В то же время образование - это жизнь определенной направленности (структурированности), т.е. для меня такая, 
где есть место свободе, любви и помощи другим, порядку и защите, трезвому осмыслению действительности и одновременно идеальным установкам. Кроме того, образование - это все-таки образование, т.е. жизнь в рамках особого исторически сложившегося института (школа, помощь со стороны взрослых, особые технологии и т.п.).

Уже в настоящее время наука и знания перестают выступать единственными формами постижения действительности, а учебные предметы - формами содержаний образования. Наряду с ними в современной культуре и производстве широко используются проекты и программы, языки искусства и инженерии, разные типы реконструкции и интерпретации, нарративы и произведения, игры и мн. др. Урок, лекция, семинар, учебник все больше осознаются как уходящие формы обучения и образования. Их начинают теснить метапредметные и рефлексивные знания, учебные игры и семинары, самостоятельные формы образования с использованием компьютера и Интернета. При этом происходит поляризация двух разных способов работы: постижения существующей реальности и творения новой.

Учащиеся, вероятно, все больше будут переходить от овладения существующими знаниями и дисциплинами к выстраиванию для себя всех необходимых учебных средств, языков и форм, не исключая конституирования самой реальности. Они постепенно будут уяснять важность и логику общих социальных условий жизни, способы их использования, свою свободу в плане творчества, с одной стороны, и зависимость от людей и общих условий - с другой. Понятно, что при таком подходе почти каждое содержание образования (особенно в высшей школе) становится уникальным и требует индивидуальной методологии построения. «В идеале, - отмечает В. Марача, теперь каждый учащийся должен получить возможность - с помощью преподавателей и тьюторов - простраивать собственный путь образования» (Марача, 2002, с. 52).

Как мы видим, пересмотр представлений о развитии предполагает изменение во многих областях жизнедеятельности человека и общества.

\section{Литература}

Аристотель. (1936). О душе. Партиздат.

Аристотель. (1952). Аналитики первая и вторая. Л.: Госполитиздат.

Выготский, Л. С. (1982). Мышление и речь. В кн. Л. С. Выготский, Собрание сочинений (т. 2). М.: Педагогика.

Выготский, Л. С. (1983). История развития высших психических функций. В кн. Л. С. Выготский, Собрание сочинений (т. 3). М.: Педагогика.

Марача В. (2002). Образование на рубеже веков: методологические соображения. В кн. Образование 21 века: достижения и перспективы. Рига.

Пузырей, А. А. (1968). Культурно-историческая теория Л.С. Выготского и современная психология. М.: Изд-во Московского университета. 
Розин, В. М. (2007). Философия образования. Этюды-исследования. М./Воронеж: МПСИ/НПО «МОДЭК».

Розин, В. М. (2011). Природа и генезис европейского искусства (философский и культурноисторический анализ). М.: Голос.

Розин, В. М. (2014). Конституирование и природа индивидуализащии. М./Тверь: «СФК-офис».

Розин, В. М. (2015а). Визуальная культура и восприятие. Как человек понимает и видит мир. М.: ЛЕНАНД.

Розин, В. М. (2015б). Детство как культурный и психологический феномен. Мир психологии, 1, 29-42.

Розин, В. М. (2015в). Память современного человека: интерпретация в свете учения о психических реальностях и личности. Мир психологии, 2, 69-79.

Священник Павел Флоренский. (1992). Детям моим. Воспоминанья прошльх дней: Генеалогические исследования. Из соловечких писем. Завещание. М.: Московский рабочий.

Толстой, Л. Н. (1948). Воскресенье. В кн. Л. Н. Толстой, Собрание сочинений (т. 11). М.: Государственное изд-во БССР.

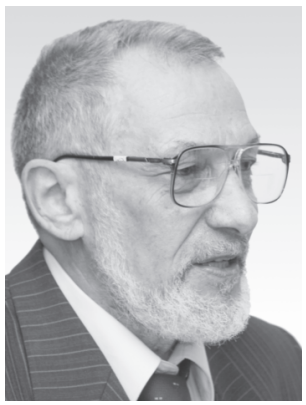

Розин Вадим Маркович - главный научный сотрудник, Институт философии РАН, доктор философских наук, профессор.

Сфера научных интересов: семиотика, культурология, гуманитарный подход.

Контакты: rozinvm@gmail.com

\title{
From L.S. Vygotsky's Views to the Contemporary Conception of Development
}

\author{
Vadim M. Rozin ${ }^{\mathrm{a}}$ \\ ${ }^{a}$ Institute of Philosophy, Russian Academy of Sciences, 12/1 Goncharnaya str., Moscore, 119019, Russian \\ Federation
}

\begin{abstract}
In the article the L.S. Vygotsky's conception of development is reviewed. Its shortcomings are discussed from the perspective of contemporary scientific notions. New conception of development is proposed, based on the ideas of step of development, cultural-historical and semiotic nature of abilities and culture of man's life. The first idea is linked to differentiation of existential situations, problems, schemas as means for solving these problems, new reality, vision and action. The second idea is about cultural-historical and semiotic understanding of human abilities. The third one is about cultural characteristic of the human developmental stages. The general provisions are illustrated by the analysis of several cases. Among these general provisions there are
\end{abstract}


some new psychological hypotheses. For example, the author analyses following important point. Aristotle in his work On the Soul creates anthropological schemas that preset new, as we would say today, psychological reality, which makes Greeks use rules, categories and patterns of thought, created by him. When Greeks got used to this new activity and reality (which, a propos, took almost two centuries), it began to seem that cognition is exactly the phenomenon, which Aristotle described, and man always had got it. The scientists still share this illusion. As V. Rozin states, other human abilities, for example memory, imagination, emotions are also not natural, innately inherent in man phenomena, but cultural-historical and semiotic formations. Another hypothesis is about periodization of psychic development. The author writes that periodization of man's development has to be based not on the concept of age, but on the concept of "culture of man's life". Referring to his works, he states that man is integral only in the biological realm, but as a cultural and spiritual being man is not integral. There are several "cultures of man's life": "culture of childhood", "culture of adolescence and youth", several "cultures of adult man". Each culture of man's life is characterized by the specifics of activities and vision (consciousness), as well as the way of socialization.

Keywords: development, situation, problem, reality, action, understanding, vision, culture of life, signs, schemes.

\section{References}

Aristotle. (1936). O dushe [On the soul]. Partizdat.

Aristotle. (1952). Analitiki pervaya i vtoraya [First and second analytics]. Leningrad: Gospolitizdat.

Maracha V. (2002). Obrazovaniye na rubezhe vekov: metodologicheskiye soobrazheniya [Education at the turn of the century: methodological conciderations]. Obrazovaniye 21 veka: dostizheniya i perspektivy [Education of the XXI century: achievements and perspectives]. Riga.

Puzyrei, A. A. (1968). Kulturno-istoricheskaya teoriya L.S. Vygotskogo i sovremennaya psikhologiya [Cultural-historical theory by L.V. Vygotsky and the contemporary psychology]. Moscow: Moscow University Press.

Rozin, V. M. (2007). Filosofiya obrazovaniya. Etyudy-issledovaniya [The philosophy of education. Essays-studies]. Moscow/Voronezh: MPSI/NPO "MODEK".

Rozin, V. M. (2011). Priroda i genezis evropeiskogo iskusstva (filosofskii i kul'turno-istoricheskii analiz) [The nature and genesis of the European art (philosophical and cultural-historical analysis]. Moscow: Golos.

Rozin, V. M. (2014). Konstituirovanie i priroda individualizatsii [The construction and nature of individualization]. Moscow/Tver: SFK-ofis.

Rozin, V. M. (2015a). Vizual'naya kul'tura i vospriyatie. Kak chelovek ponimaet $i$ vidit mir [Visual culture and perception. How man understands and sees the world]. Moscow: LENAND.

Rozin, V. M. (2015b). Childhood as a cultural and psychological phenomenon. Mir Psikhologii, 1, 29-42.

Rozin, V. M. (2015c). Memory of the modern person: interpretation in the light of the doctrine on mental realities and personality. Mir Psikhologii, 2, 69-79.

Pavel Florenskii, priest. (1992). Detyam moim. Vospominan'ya proshlykh dnei: Genealogicheskie issledovaniya. Iz solovetskikh pisem. Zaveshchanie [To my children. Memories from the days past: Genealogical studies. From letters from Solovki. Last will]. Moscow: Moskovskii Rabochii. 
Tolstoy, L. N. (1948). Voskresen'e [Resurrection]. In L. N. Tolstoy, Sobranie sochinenii [Collected works] (Vol. 11). Moscow: Gosudarstvennoe Izdatel'stvo BSSR.

Vygotsky, L. S. (1982). Myshlenie i rech' [Thinking and speech]. In L. S. Vygotsky, Sobranie sochinenii [Collected works] (Vol. 2). Moscow: Pedagogika.

Vygotsky, L. S. (1983). Istoriya razvitiya vysshikh psikhicheskikh funktsii [The history of development of higher psychic functions]. In L. S. Vygotsky, Sobranie sochinenii [Collected works] (Vol. 3). Moscow: Pedagogika.

Vadim M. Rozin - leading research fellow, Institute of Philosophy, Russian Academy of Sciences, D. Sc., professor.

Research area: semiotics, culturology, humanistic approach.

E-mail: rozinvm@gmail.com 